\title{
EFEKTIFITAS TAWAS DARI MINUMAN KALENG BEKAS SEBAGAI KOAGULAN UNTUK PENJERNIH AIR
}

\section{THE EFFECTIVENESS OF ALUM FROM USED BEVERAGES AS COAGULANTS FOR WATER CLEANER}

\author{
Laila Febrina ${ }^{1}$, Ardhila Zilda ${ }^{2}$ \\ ${ }^{1}$ Teknik Lingkungan, Fakultas Teknik, Jurusan Universitas Sahid Jakarta, Jl. Prof. Dr. Soepomo, SH No.84 \\ Tebet Jakarta Indonesia, Email: lailahardian@gmail.com \\ ${ }^{2}$ Teknik Lingkungan, Fakultas Teknik, Jurusan Universitas Sahid Jakarta, Jl. Prof. Dr. Soepomo, SH No.84 \\ Tebet Jakarta Indonesia
}

\begin{abstract}
ABSTRAK
Persediaan air bersih di Indonesia semakin terbatas, dimana sumber air untuk memenuhi kebutuhan hidup masyarakat pada saat ini sebagian besar sudah tercemar karena kegiatan manusia itu sendiri. Berdasarkan hal tersebut dirasa perlu melakukan pengolahan air lebih lanjut guna mendapatkan supply air bersih. Dalam pengolahan air bersih salah satunya dilakukan proses koagulasi yang menggunakan koagulan tawas sebagai proses penjernihan air. Ada banyak koagulan yang dapat digunakan antara lain tawas atau aluminium sulfat. Pada penelitian ini dilakukan penelitian pembuatan koagulan dari kaleng bekas. Unsur aluminium yang terdapat pada kaleng bekas tersebut yang dimanfaatkan untuk pembuatan tawas. Pengamatan dilakukan terhadap hasil tawas dari kaleng bekas dengan mengetahui rendemen tawas yang dihasilkan dari kaleng bekas, efektifitas tawas dari kaleng bekas, dan hasil parameter kekeruhannya terhadap air yang diuji dengan skala laboratorium menggunakan jartest. Variasi dosis larutan induk tawas yang terbuat dari limbah kaleng bekas dengan dosis 15, 20, 25, 30, 35, dan 40 ppm Setelah itu dicari efektivitas tawas yang terbuat dari limbah kaleng dengan membandingkan parameter kekeruhan terhadap Permenkes No. 492/MenKes/Per/IX/2010.
\end{abstract}

Kata Kunci: Tawas, Koagulan, Penjernih Air

\begin{abstract}
The supply of clean water in Indonesia is increasingly limited, where most of the water sources to meet the needs of people's lives are currently polluted due to human activities themselves. Based on this, it is deemed necessary to carry out further water treatment in order to obtain a clean water supply. One of the ways to treat clean water is the coagulation process using alum as a water purification process. There are many coagulants that can be used, including alum or aluminum sulfate. In this study, research was conducted on the manufacture of coagulants from used cans. The aluminum element contained in the used cans is used for making alum. Observations were made on the results of alum from used cans by knowing the yield of alum produced from used cans, the effectiveness of alum from used cans, and the results of the turbidity parameters of water tested on a laboratory scale using jartest. Variations in dosage of alum mother liquor made from used cans with doses of 15, 20,25, 30, 35, and 40 ppm. 492/MenKes/Per/IX/2010.
\end{abstract}

Keywords: Alum, Coagulant, Water Cleaner

\section{Pendahuluan}

Penyediaan air bersih harus terus ditunjang untuk ditingkatkan, baik melalui pengolahan air baku maupun air limbah yang berpotensi mencemari lingkungan. Masyarakat kita saat ini masih belum lepas dari kesulitan mendapatkan air bersih terutama saat musim kemarau. 
Nampak ada kecenderungan semakin sulitnya mendapatkan air bersih di masa mendatang. Karenanya produk-produk industri yang diperlukan untuk pengolahan air (water treatment) harus diupayakan diproduksi di dalam negeri seperti tawas (alum, $\left.\mathrm{Al}_{2}\left(\mathrm{SO}_{4}\right)_{3} \cdot \mathrm{nH}_{2} \mathrm{O}\right), \mathrm{PAC}($ Poly Aluminum Chloride), kaporit, ozon, kapur (hydrated lime, $\mathrm{Ca}(\mathrm{OH}) 2)$, zeolit, pasir aktif (pengoksidasi), karbon aktif, dan pasir kuarsa(Aziz.M,2009).

Kaleng minuman termasuk ke dalam sampah organik, berbahan dasar Aluminium. Bahan dasar aluminium sangat tahan lama dan sulit untuk dapat terurai. Daur ulang merupakan sebuah solusi yang tepat bagi aluminium dalam menekan permasalahan lingkungan. Salah satu cara mendaur ulang aluminium bekas yaitu mengolahnya menjadi bahan koagulan penjernih air atau dikenal dengan tawas.

Aluminium sulfat $\left[\mathrm{Al}_{2}\left(\mathrm{SO}_{4}\right)_{3}\right]$ atau tawas merupakan salah satu bahan kimia yang sangat diperlukan baik dalam industri pengolahan air. Sebagian besar konsumsi tawas dalam negeri dipergunakan oleh industri penjernih air yaitu sebesar 56,90\%, kemudian diikuti oleh industri kertas yaitu 35,05\% dan sisanya industri--industri lainnya. Seperti industri kimia dasar, industri makanan dan minuman, industri pupuk, dan sebagainya. Kebutuhan tawas di Indonesia dari tahun ke tahun menunjukkan angka yang terus meningkat seiring dengan berkembangnya industri. Berdasarkan data statistik kebutuhan tawas di Indonesia berkisar anatar 60.000-70.000 ton / tahun, hampir 40\% kebutuhan tawas di Indonesia masih impor.

Aluminium ini dapat dibuat dalam berbagai bentuk, dapat ditempa menjadi lembaran, ditarik menjadi kawat dan diekstrusi menjadi batangan dengan bermacam-macam penampang. Penggunaan aluminium terus mengalami peningkatan dari tahun ke tahun. Pada akhirnya jumlah sampah kaleng minuman pun ikut bertambah. Dari data Deputi Pencemaran Kementrian Negara Lingkungan Hidup (KLH) menyebutkan, setiap individu metode adsorbsi dengan kabon aktif ataupun dengan zeolit, mencakup kondisi proses, tingkat penyisihan dan kualitas hasil olahan rata-rata menghasilkan 0,8 kilogram sampah dalam satu hari dimana 2 persennya adalah kaleng minuman.

Dengan asumsi ada sekitar 220 juta penduduk di Indonesia, maka limbah kaleng minuman yang tertimbun mencapai 3.520 ton per hari, sedangkan jumlah timbunan sampah nasional diperkirakan mencapai 176.000 ton per hari. Sementara data KLH 2015 menunjukkan, jumlah timbunan sampah di 194 kabupaten dan kota di Indonesia mencapai 666 juta liter atau setara 38,5 juta ton di mana komposisi limbah kaleng minuman mencapai $2 \%$ atau 0,7 juta ton. Berdasarkan data persampahan Indonesia tahun 2015, diketahui bahwa jumlah sampah kaleng yang utamanya mengandung aluminium di Indonesia mencapai 2\% dari total sampah setiap tahunnya, dan dibutuhkan waktu 400 tahun untuk dapat menguraikan limbah kaleng secara alami.

Penggunaan aluminium semakin lama semakin meningkat. Apabila tidak diolah dengan baik dapat mencemari lingkungan . Untuk mengatasi limbah aluminium tersebut, cara yang dapat dilakukakn adalah dengan recycle. Recycle adalah mengolah kembali (daur ulang) limbah menjadi barang atau produk baru yang bermanfaat. Mengubahnya limbah aluminium dari kaleng bekas minuman menjadi tawas untuk pengolahan air besih adalah salah satu alternatifnya. Kaleng bekas yang dapat digunakan antara lain kaleng minuman ringan seperti pocari sweat, Cap Kaki Tiga, Coca Cola dan minuman nescafe yang dibuang sehabis diminum. Sisa pembuangan tersebut dapat dimanfaatkan dengan menggunakan pengolahan khusus dan penambahan zat kimia lain supaya alumunim dapat dipisahkan dari kaleng. Optimalisasi proses daur ulang juga dapat menambah nilai ekonomis dari limbah kaleng

\section{Metode Penelitian}

Penelitian ini dilakukan dalam 2 tahap penelitian. Yaitu tahapan pendahuluan dan penelitian utama. Tahap yang pertama adalah membuat tawas dari aluminium yang berasal dari minuman kaleng bekas. Bagan alir tahapan penelitian disajikan pada gambar 1 berikut ini : 


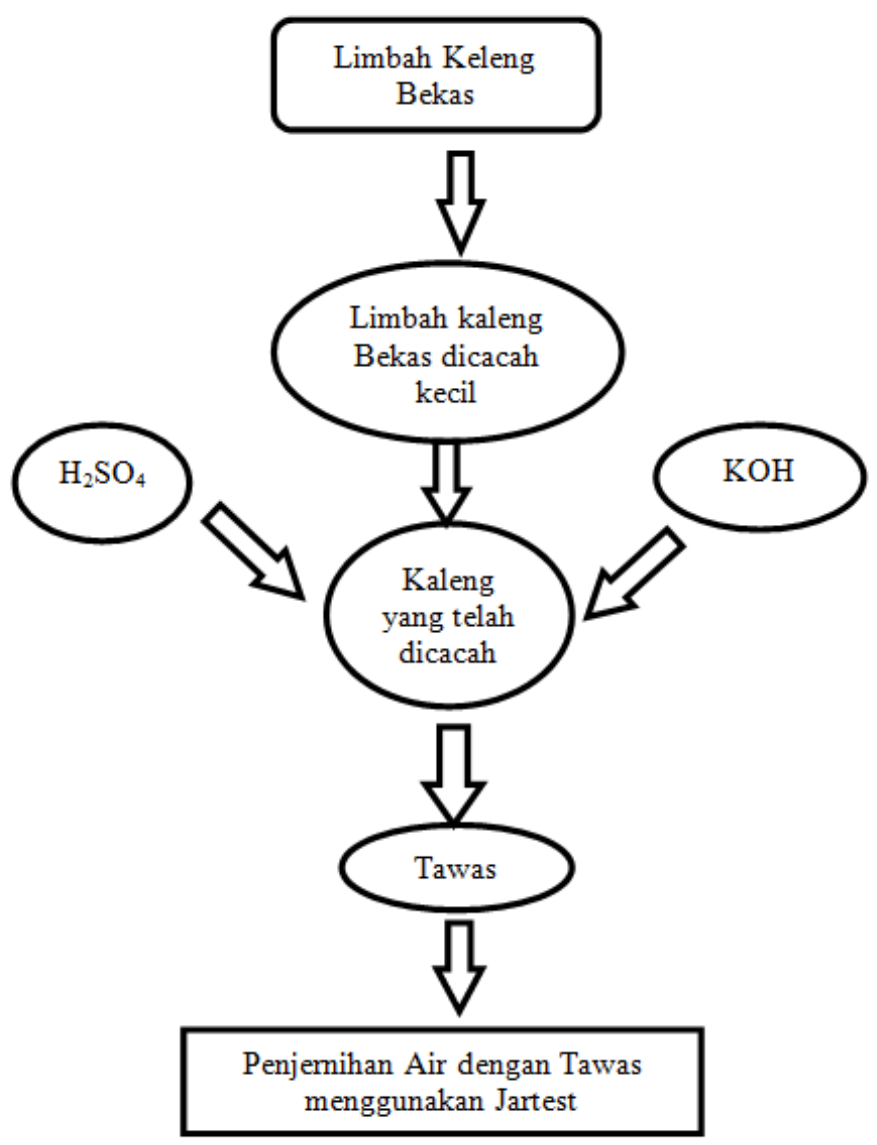

Gambar 1. Kerangka Penelitian

Limbah keleng bekas dicacah terlebih dahulu kemudian diberi perlakuan dengan penambahan $\mathrm{KOH}$ dan $\mathrm{H}_{2} \mathrm{SO}_{4}$ guna menghasilkan tawas diingin. Tawas yang telah diperoleh digunakan untuk penjernihan air yag dilakukan dengan metode jartest.

\subsection{Tahapan Pembuatan Rawas dari Kaleng Minuman Bekas}

Tahapan proses pembuatan tawas dari kaleng bekas, yaitu:

1. Ditimbang potongan kaleng bekas sebanyak 5 gram,

2. Dimasukkan ke dalam beaker glass $300 \mathrm{ml}$,

3. Ditambahkan $\mathrm{KOH} 7 \%$ sebanyak $20 \mathrm{ml}$ (reaksi dihentikan sampai tidak ada gelembunggelembung gas),

4. Hasil larutan disaring dan didinginkan,

5. Ditambahkan $12 \mathrm{ml} \mathrm{H} 2 \mathrm{SO} 46 \mathrm{M}$ sambil diaduk,

6. Dinginkan larutan di dalam es (kristal tawas akan terbentuk dalam waktu 20 menit),

7. Dicuci dengan $20 \mathrm{ml}$ etanol $50 \%$ (etanol berfungsi untuk membersihkan kotoran yang masih menempel pada tawas dan mempercepat pengeringan),

8. Dipanaskan di oven pada suhu 600 - $800 \mathrm{C}$ selama 1 jam,

9. Didinginkan dan ditimbang.

Sumber: (Manuntun Manurung dan Irma Fitria Ayuningtyas ; 2010) 


\subsection{Tahapan Setelah Proses Penelitian}

Setelah tawas dari kaleng bekas dihasilkan, maka tahapan setelah proses penelitian adalah:

1. Menganalisa tawas yang terbuat dari limbah kaleng bekas dengan metode jar test. Kualitas optimum sebagai koagulan penjernih air.

2. Membandingkan kualitas air hasil penjernihan menggunakan tawas yang terbuat dari limbah tawas yang terbuat dari kaleng bekas diuji dengan metode jar test untuk menentukan dosis kaleng bekas dengan kualitas air bersih berdasarkan PERMENKES No.492/MENKES/PER/IV/2010 tentang persyaratan kualitas air minum untuk mengetahui kualitas tawas.

3. Membandingkan efektivitas tawas yang terbuat dari limbah kaleng bekas dengan tawas yang dijual secara komersil. Tujuannya untuk mengetahui apakah tawas yang terbuat dari kaleng bekas kualitasnya sama dengan tawas yang dijual secara komersial

\subsection{Langkah-langkah Pengujian dengan Jar Test}

Langkah-langkah pengujian dengan Jar Test adalah sebagai berikut:

1. Dibuat larutan induk tawas 5000 ppm dengan melarutkan 2,5 gram tawas dari limbah kaleng bekas ke dalam $500 \mathrm{ml}$ aquadest,

2. Disiapkan sample air baku yang akan diolah dan dimasukkan ke dalam 6 buah beaker glass 1 liter,

3. Dibuat variasi dosis larutan induk tawas yang terbuat dari limbah kaleng bekas dengan dosis 15, 20, 25, 30, 35, dan 40 ppm (variasi dosis dipilih dari dosis alum yang dijual secara komersial)

4. Ditambahkan larutan induk ke dalam masing-masing sampel air baku,

5. Dilakukan pengadukan cepat selama 10 menit dengan kecepatan $100 \mathrm{rpm}$ dan dilanjutkan dengan pengadukan lambat selama 20 menit dengan kecepatan $20 \mathrm{rpm}$,

6. Ditunggu selama 30 menit proses terjadinya pengendapan

Catatan: Jika hasil larutan tidak terbentuk flok dan air masih keruh, dibuat variasi dosis 50, 100, 150, 200, 250 dan 300 ppm. Setelah itu, diulangi pengujian nomer 4-6.

7. Dilakukan juga pengujian nomer 1-6 untuk tawas murni yang dijual secara komersil untuk perbandingan

Data yang diperoleh dalam penelitian ini adalah data primer.Pengumpulan data primer dilakukan dengan cara melakukan pengujian terhadap kandungan tawas yang dibuat dari kaleng bekas. Hasil tawas tersebut dibandingkan efektifitasnya terhadap pengujian air baku dengan menggunakan metode jartest.

Metode Jar test digunakan untuk menentukan dosis optimum tawas yang terbuat dari kaleng bekas. Kualitas air hasil penjernihan menggunakan tawas yang terbuat dari limbah kaleng bekas dibandingkan dengan parameter air bersih dengan analisa deskriptif. Setelah itu, membandingkan efektivitas tawas yang terbuat dari limbah kaleng bekas dengan tawas yang dijual secara komersil dari hasil percobaan skala laboratorium dan analisa data perhitungan matematika. Perhitungan matematika untuk efektivitas tawas dapat dihitung dengan rumus. Nilai efektivitas digunakan untuk mengetahui penurunan kadar krom dari proses penelitian yang telah dilakukan.

Keterangan :

$\%$ Efektifitas Tawas $=\underline{X}_{1}-\mathrm{X}_{2} \times 100 \%$

$\mathrm{X}_{1}$

$\mathrm{X}_{1}=$ Nilai kekeruhan sampel sebelum menggunakan Tawas (NTU)

$\mathrm{X}_{2}=$ Nilai kekeruhan sampel sesudah menggunakan Tawas (NTU) 
Rancangan penelitian yang disusun pada penelitian ini adalah sebagai berikut :

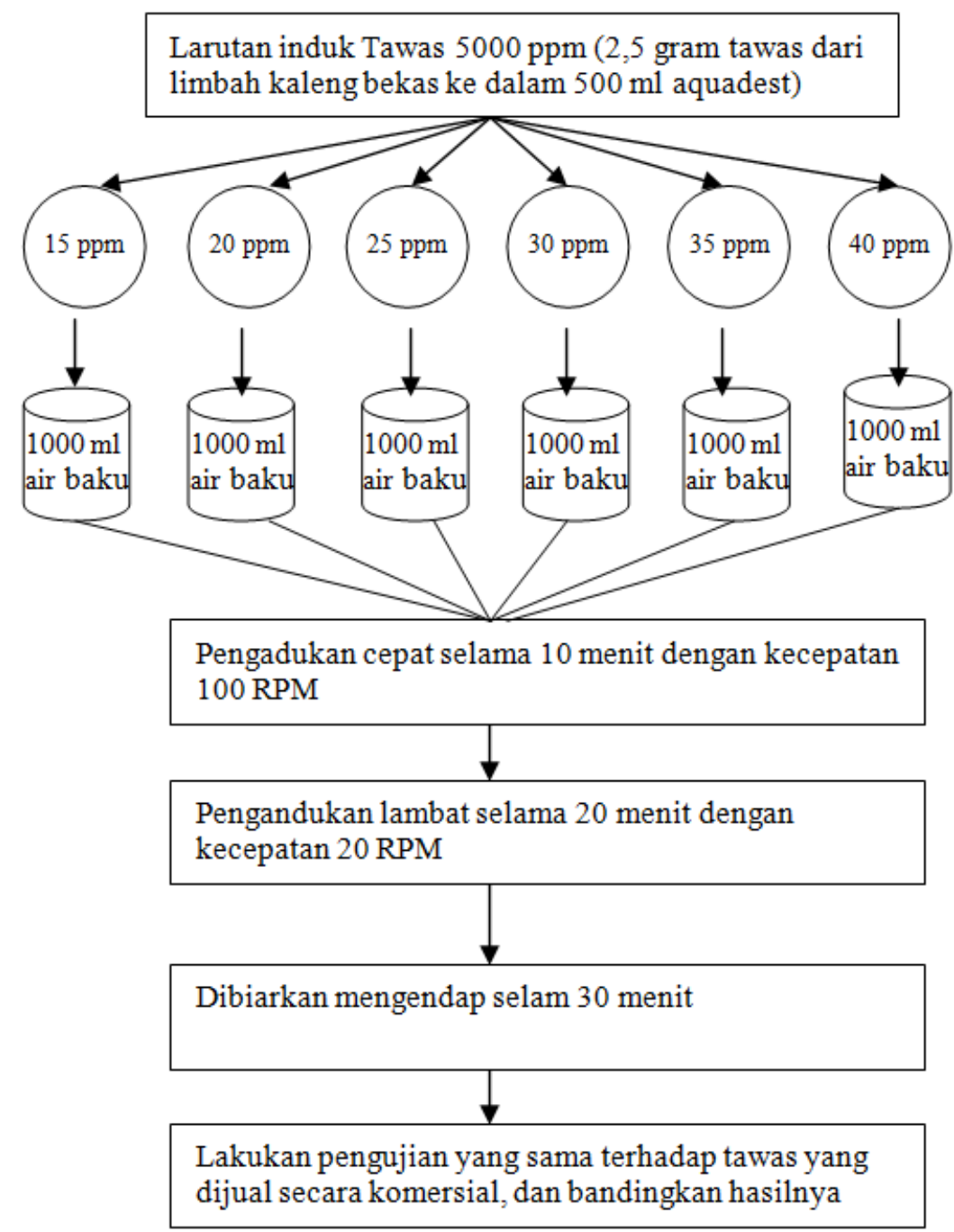

Gambar 2. Rancangan Penelitian

\section{Hasil Penelitian Dan Pembahasan}

Limbah kaleng minuman bekas adalah sampah anorganik yang tidak dapat didegradasi oleh bakteri dan tidak dapat diurai secara alami. Dalam jumlah banyak limbah kaleng minuman bekas ini dapat mengganggu kelestarian lingkungan. limbah kaleng minuman bekas ini dapat digunakan untuk membuat tawas karena mengandung logam alumunium (Al). Oleh karena itu, recycle kaleng minuman bekas dapat sebagai salah satu alternatif untuk pembuatan tawas. Kandungan Alumunium dalam kaleng minuman bekas berkisar antara 1,4 - $16 \%$ tergantung kualitas kaleng minuman tersebut.

Selain itu, pada penelitian Irma Fitria Ayuningtyas (2010) melakukan penelitian tentang kandungan alumunium pada kaleng bekas dengan menggunakan metode analisa kuantitatif menggunakan spectrofotometer yaitu Kandungan alum pada kaleng bekas Pocari Sweat = 11,8\%, kaleng bekas Larutan Cap Kaki Tiga $=5,7 \%$, kaleng bekas Greensands $=16,0 \%$, kaleng bekas Coca-Cola $=9,9 \%$, kaleng bekas Delmonte $=1,4 \%$ dan kaleng bekas Nescafe $=7,7 \%$.

Pemanfaatan limbah kaleng bekas lainnya pada penelitian Yusraini Dian Inayati Siregar (2010) melakukan penelitian tentang pembuatan gas hidrogen dari kaleng bekas dengan menggunakan optimasi penggunaan katalis (suasana asam, basa dan netral) yang digunakan untuk produksi hidrogen yaitu gas hidrogen dapat diproduksi dengan menggunakan limbah 
alumunium foil dan limbah alumunium dari kaleng minuman pada suasana basa $(\mathrm{NaOH}, \mathrm{KOH})$. Produksi hidrogen optimum adalah sebesar 0,006 gram dari 0,05 gram limbah alumunium (alumunium foil).

Kaleng bekas mengandung logam alumunium ( $\mathrm{Al}$ ) yang dapat kita gunakan untuk pembuatan tawas kalium. Pembuatan tawas dari kaleng bekas memerlukan bahan kimia tambahan yaitu Kalium hidroksida dan Asam sulfat. Kalium hidroksida berguna untuk mengikat ion logam Alumunium lalu direaksikan dengan Asam Sulfat. Pada reaksi dengan Asam Sulfat maka senyawa sulfat ditarik untuk membentuk produk Alum atau Tawas $\mathrm{Al} 2(\mathrm{SO} 4) 3$.

\subsection{Persiapan Awal untuk Kaleng Bekas}

Kaleng bekas sebelum digunakan untuk membuat tawas harus dilakukan persiapan awal terlebih dahulu, yaitu dengan cara:

1. Kaleng bekas dibersihkan terlebih dahulu dan dikeringkan, (kaleng bekas berasal dari berbagai jenis seperti: pocari sweat, cap kaki tiga, coca-cola, dan nescafe),

2. Kaleng bekas diamplas, (Gambar 3)

3. Lalu dipotong menjadi potongan kaleng yang sangat kecil.(Gambar 4)

Tidak ada ketetapan ukuran potongan kaleng bekas, semakin kecil potongan kaleng semakin mudah bereaksi dengan $\mathrm{KOH}$ karena semakin kecil ukuran partikel, luas permukaanya semakin besar. Sehingga tumbukan antar partikel semakin banyak akibatnya laju reaksi semakin cepat. Berdasarkan teori luas permukaan yang berbunyi "semakin besar luas permukaan semakin cepat laju reaksinya".

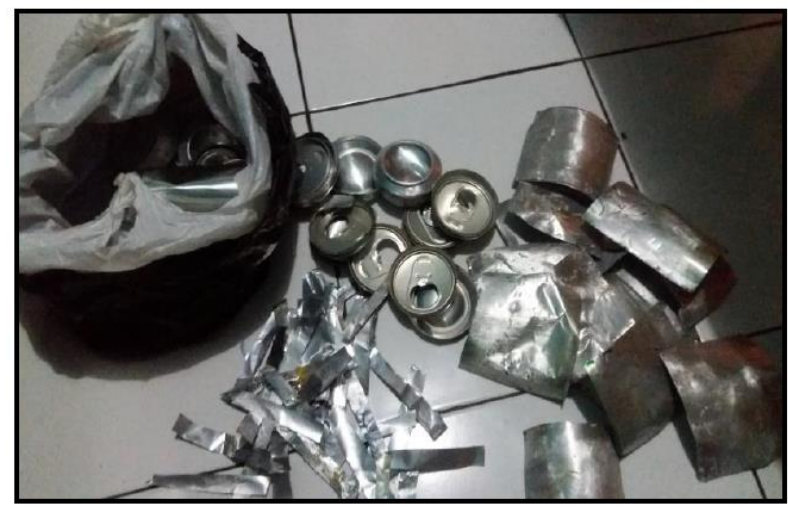

Gambar 3. Kaleng bekas yang sudah diamplas

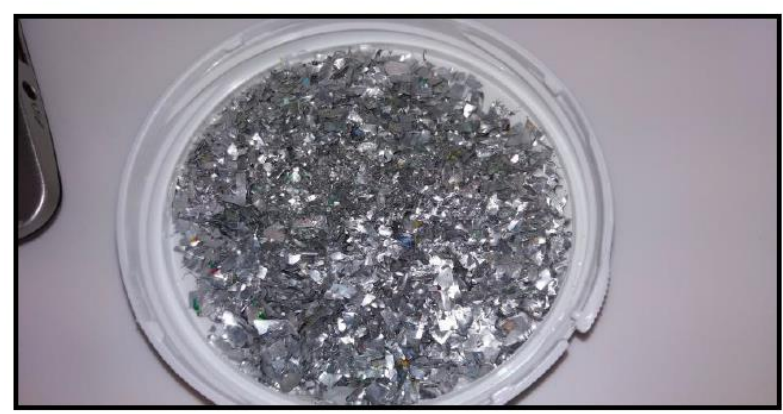

Gambar 4. Kaleng Bekas Yang Sudah Dipotong Kecil 


\subsection{Pengujian Reaksi Dengan Kalium Hidroksida (KOH)}

Pengujian reaksi dengan kalium hidroksida dilakukan pada sebelum proses pembuatan tawas dari kaleng bekas. Pengujian ini bertujuan untuk mengetahui konsentrasi $\mathrm{KOH}$ yang tepat untuk pembuatan tawas dari kaleng minuman bekas. Langkah-langkah pengujiannya sama dengan proses pembuatan tawas dari kaleng minuman bekas. Hanya saja, penambahan $20 \mathrm{ml}$ Kalium Hidroksida $(\mathrm{KOH})$ dibuat variasi konsentrasi, yaitu: 1, 3, 5, 7, 10, 12, 15 dan 20\%. Variasi ini didapat dari prosedur penelitian lain yaitu penelitian Ayuninngtyas,F (2010). Pada penelitian tersebut konsentrasi $\mathrm{KOH}$ yang digunakan yaitu $\mathrm{KOH} 7 \%$ sehingga variasi konsentrasi $\mathrm{KOH}$ dibuat kurang dari 7\% dan lebih dari 7\%. Hasil pengujian $\mathrm{KOH}$ dapat dilihat pada gambar 3

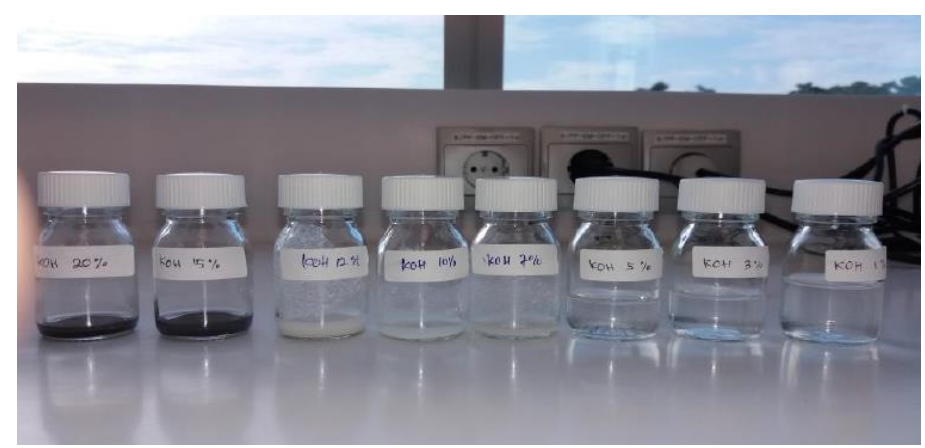

Gambar 5. Hasil Pengujian Kaleng Tawas Dengan KOH

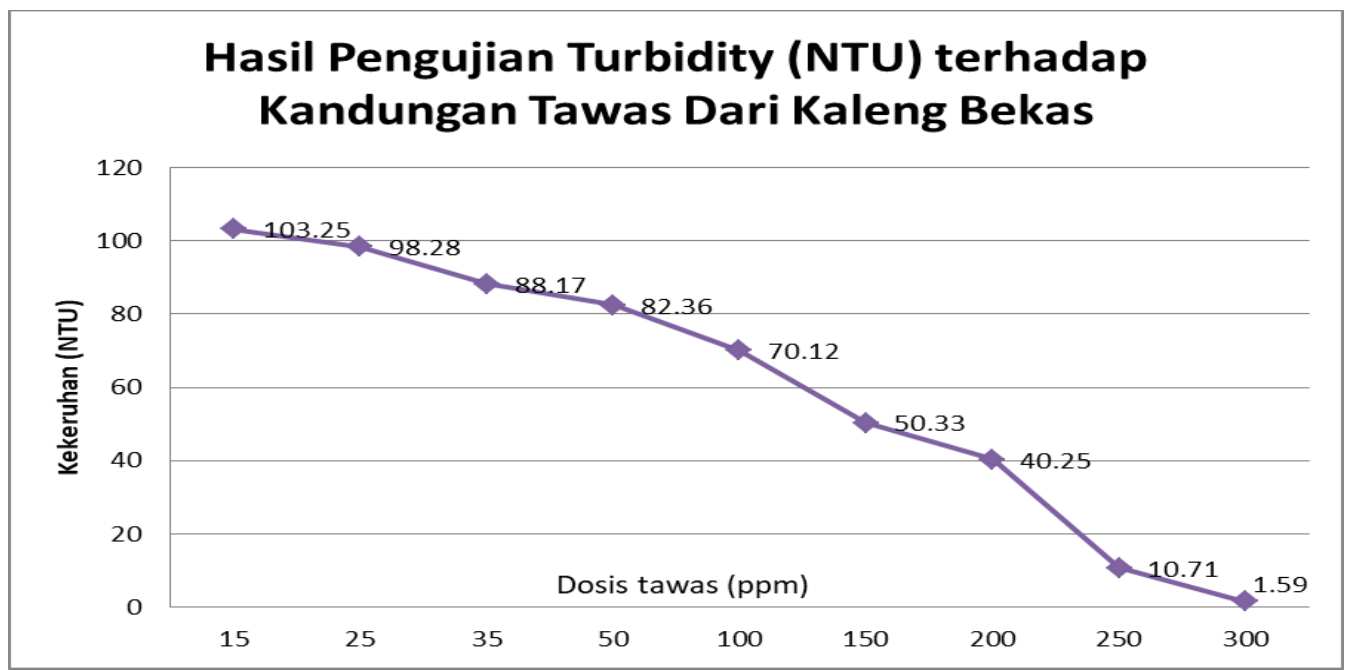

Gambar 6. Grafik Pengujian Turbidity terhadap Kandungan Tawas

Tabel 1. Hasil Pengujian Dengan Tawas dari Kaleng Bekas

\begin{tabular}{|l|l|l|l|l|}
\hline $\begin{array}{l}\text { Kandungan } \\
\text { Tawas kaleng }\end{array}$ & $\begin{array}{c}\text { Berat tawas } \\
\text { per 1000 ml }\end{array}$ & $\begin{array}{l}\text { Turbidity } \\
\text { (NTU) }\end{array}$ & $\begin{array}{l}\text { Baku Mutu } \\
\text { Air Bersih }\end{array}$ & $\begin{array}{l}\text { Baku Mutu } \\
\text { Air Minum }\end{array}$ \\
\hline $250 \mathrm{ppm}$ & 0,25 gram & 10,71 NTU & 25 NTU & 5 NTU \\
\hline $300 \mathrm{ppm}$ & 0,30 gram & 1,59 NTU & & \\
\hline
\end{tabular}


Tabel 2. Pengujian Dengan Tawas Murni 50 ppm

\begin{tabular}{|l|l|l|l|l|}
\hline Parameter & $\begin{array}{l}\text { Sebelum } \\
\text { Pemberian } \\
\text { Tawas }\end{array}$ & $\begin{array}{l}\text { Sesudah } \\
\text { Pemberian } \\
\text { Tawas }\end{array}$ & $\begin{array}{l}\text { Baku Mutu } \\
\text { Air Bersih }\end{array}$ & $\begin{array}{l}\text { Baku Mutu } \\
\text { Air Minum }\end{array}$ \\
\hline Kekeruhan & $103 \mathrm{NTU}$ & $1,45 \mathrm{NTU}$ & $25 \mathrm{NTU}$ & $5 \mathrm{NTU}$ \\
\hline $\mathrm{pH}$ & 7,3 & 6,9 & $6-9$ & $6-9$ \\
\hline Temperatur & $26,8^{\circ} \mathrm{C}$ & $27,2^{\circ} \mathrm{C}$ & $26,8\left( \pm 3^{\circ} \mathrm{C}\right)$ & $26,8\left( \pm 3^{\circ} \mathrm{C}\right)$ \\
\hline Bau & Berbau & Tidak Berbau & Tidak Berbau & Tidak Berbau \\
\hline
\end{tabular}

Sehingga dapat disimpulkan bahwa untuk penjernihan air dengan tawas yang terbuat dari kaleng minuman bekas memerlukan tawas 6 kali lebih banyak dibandingkan dengan menggunakan tawas murni.

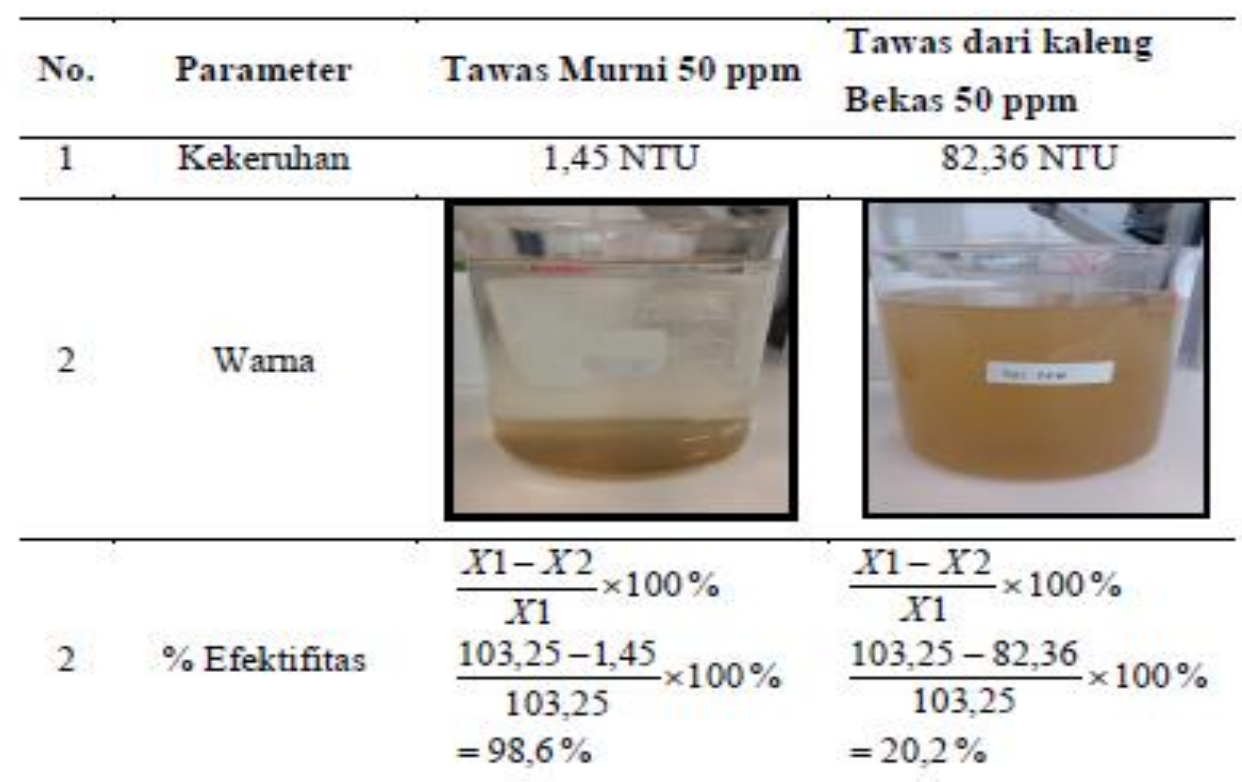

Gambar 7. Perbandingan Tawas Murni dengan Tawas dari Kaleng Bekas

Sehingga dapat diperoleh bahwa tawas murni lebih efektif dibandingkan dengan tawas yang terbuat dari kaleng minuman bekas. Pembuatan tawas dari kaleng minuman bekas dilakukan 3 kali percobaan (Triplo) dengan rata-rata bobot tawas yang didapat dari 5 gram kaleng minuman bekas sebesar 0,9 gram. Jika bobot satu kaleng minuman bekas berkisar 1217 gram, maka satu kaleng minuman bekas dapat menghasilkan tawas sebesar 2,5-3,5 gram tawas. 


\section{Kesimpulan}

Berdasarkan analisis hasil penelitian dapat di simpulkan:

1. Pembuatan alum dari kaleng bekas mempunyai metode yang sederhana. Penggunaan $\mathrm{KOH}$ yang efektif pada pembuatan tawas dari kaleng minuman bekas konsentrasi adalah $7 \%$ dan $\mathrm{H} 2 \mathrm{SO} 4$ yang efektif pada konsentrasi $6 \mathrm{M}$.

2. Tawas yang terbuat dari limbah kaleng bekas terbukti mampu menjadi koagulan, hanya saja dosis yang dibutuhkan agar dapat menjernihkan air jauh lebih banyak dibandingkan dengan dosis tawas murni. Perbandingan jumlah penggunaan tawas dari kaleng minuman bekas dengan tawas murni yang dijual secara komersial adalah 6:1.

3. Efektivitas tawas murni yaitu $98,6 \%$ sedangkan efektifitas tawas yang terbuat dari kaleng minuman bekas yaitu 20,2\%.

4. Rendemen hasil pembuatan tawas dari kaleng bekas adalah $18 \%$

\section{Daftar Pustaka}

Ayundyahrini, Meilinda,. Rusdhianto Effendie A. K, \& Nurlita Gamayanti. (2013). Estimasi Dosis Alumunium Sulfat pada Proses Penjernihan Air Menggunakan Metode Genetic Algorithm. Jurnal, Universitas Institut Teknologi Sepuluh Nopember, Surabaya, 2013. Jurnal Teknik Pomits Vol. 2, No. 2, (2013) Issn: 2337-3539

Ayuningtyas, Irma Fitria, (2010). Kandungan Aluminium dalam Kaleng Bekas dan Pemanfaatannya dalam Pembuatan Tawas. Universitas Udayana, 2010

Intan Ramadhani, Gary, Atiek Moesriati. (2013). Pemanfaatan Biji Asam Jawa (Tamarindusindica) Sebagai Koagulan Alternatif dalam Proses Menurunkan Kadar COD dan BOD dengan Studi Kasus pada Limbah Cair Industri Tempe. Jurnal, Universitas Institut Teknologi Sepuluh Nopember, Surabaya, 2013. Jurnal Teknik Pomits Vol. 2, No. 1, (2013) Issn: 2337-3539

Manurung, Manuntun,. Irma Fitria Ayuningtyas. (2010). Kandungan Aluminium Dalam Kaleng Bekas Dan Pemanfaatannya Dalam Pembuatan Tawas. Universitas Udayana, Bukit Jimbaran. Jurnal Kimia 4 (2), Juli 2010

Yahya, A., (1988), Analisis Sifat Fisik Kimia Air, Pusat Penelitian Lingkungan Hidup Institut Pertanian Bogor. 